\title{
The effect of potent CYP2D6 inhibition on the pharmacokinetics and safety of deutetrabenazine in healthy volunteers
}

\author{
F. Schneider ${ }^{1}$ (D) D. Stamler ${ }^{2} \cdot$ M. J. Bradbury² $\cdot$ P. S. Loupe ${ }^{3} \cdot$ M. F. Gordon ${ }^{3} \cdot$ L. Rabinovich-Guilatt $^{4}$
}

Received: 18 May 2021 / Accepted: 12 August 2021 / Published online: 1 September 2021

(c) The Author(s) 2021

\begin{abstract}
Purpose Deutetrabenazine is a deuterated form of tetrabenazine with a confirmed lower rate of CYP2D6 metabolism of the active metabolites, $\alpha$ - and $\beta$-HTBZ. In this study, we assessed the effect of paroxetine, a potent CYP2D6 inhibitor, on the pharmacokinetics and safety of deutetrabenazine and its metabolites.

Methods In this open-label sequential drug-drug-interaction study, 24 healthy adults who were CYP2D6 extensive or intermediate metabolizers received a single deutetrabenazine $22.5-\mathrm{mg}$ oral dose on days 1 and 11 and a single paroxetine 20-mg oral daily dose on days 4-12. Pharmacokinetics of deutetrabenazine and its metabolites were assessed on days 1-4 and 11-14. Paroxetine trough concentrations were obtained pre-dose on days 9-13. Safety examinations occurred throughout the study. Results Paroxetine administered under steady-state conditions, increased exposure of the deuterated active metabolites, $\alpha$-HTBZ (1.2-fold $\mathrm{C}_{\max }$ and 1.8-fold $\mathrm{AUC}_{0-\infty}$ ) and $\beta$-HTBZ (2.1-fold $\mathrm{C}_{\max }$ and 5.6-fold $\mathrm{AUC}_{0-\infty}$ ), and correspondingly, 1.6-fold $\mathrm{C}_{\max }$ and threefold $\mathrm{AUC}_{0-\infty}$ for total $(\alpha+\beta)$-HTBZ. Sixteen subjects reported 45 adverse events and most were mild. Headache was the most common AE reported 8 times by 7 subjects ( 5 following paroxetine alone; 2 following deutetrabenazine + paroxetine).

Conclusions Paroxetine-induced increases in exposure to the active deutetrabenazine metabolites were less than those previously reported for tetrabenazine, a finding expected to reduce the burden of drug interaction. In addition, single doses of $22.5 \mathrm{mg}$ deutetrabenazine, when given alone or in the presence of steady-state paroxetine ( $20 \mathrm{mg}$ daily), were safe.
\end{abstract}

Keywords Deutetrabenazine $\cdot$ Tetrabenazine $\cdot$ Deuteration $\cdot$ CYP2D6 inhibition

\section{Introduction}

Deutetrabenazine (Austedo, Teva Pharmaceutical Industries Ltd) and tetrabenazine (Xenazine, Lundbeck) are approved to treat chorea associated with Huntington's disease $[1,2]$. Deutetrabenazine is also approved to treat tardive dyskinesias [3, 4]. Both compounds, through their active $\alpha$ - and $\beta$-dihydrotetrabenazine (HTBZ) metabolites, function as vesicular monoamine transporter 2 (VMAT2)

F. Schneider

frank.schneider02@teva.de

1 Teva Pharmaceutical Industries Ltd, Ratiopharm GmbH, Ulm, Germany

2 Formerly of Teva Pharmaceutical Industries Ltd, Currently Alterity Therapeutics Limited, Newark, CA, USA

3 Teva Pharmaceutical Industries Ltd, West Chester, PA, USA

4 Teva Pharmaceutical Industries Ltd, Netanya, Israel inhibitors, a class of drugs that acts by depleting presynaptic monoamines, in particular dopamine, in the basal ganglia.

Deutetrabenazine was rationally designed as a deuterated form of tetrabenazine in which two O-linked methyl groups $(\mathrm{O}-\mathrm{CH} 3)$ of the tetrabenazine molecule have been replaced by two trideuteromethyl groups (O-CD3). Studies in healthy volunteers confirmed that the deuteration at the selected positions attenuates the metabolic breakdown of $\alpha$-HTBZ and $\beta$-HTBZ by CYP2D6 with corresponding reductions in the formation of the less active $\mathrm{O}$ demethylated metabolites, thus leading to doubling of the active metabolite half-lives without formation of novel metabolites [5, 6]. A schematic showing deutetrabenazine metabolism from Schneider et al. 2020 is shown as Supplemental Fig. S1 [5]. As a consequence, deutetrabenazine can be administered at lower doses relative to tetrabenazine to achieve a comparable systemic exposure to the active $\alpha$ and $\beta$-HTBZ metabolites with a reduction in the maximal 
concentration $\left(\mathrm{C}_{\max }\right)$. The increased half-life and lower $\mathrm{C}_{\max }$ result in reduced peak-to-trough fluctuations of the active metabolites at steady state compared to tetrabenazine. Further, the longer half-life has led to twice daily dosing of deutetrabenazine in all dosing regimens $[1,3,4]$ whereas tetrabenazine may require up to three times daily dosing $[7,8]$. Strong CYP2D6 inhibitors, such as paroxetine, are known to significantly increase plasma levels of $\alpha$ - and $\beta$-HTBZ after tetrabenazine administration [7, 9]. Based on this interaction, recommended doses of tetrabenazine in patients taking strong CYP2D6 inhibitors or those with poor CYP2D6 metabolism phenotypes must be reduced. Since deuteration attenuates the CYP2D6 metabolism of $\alpha$ - and $\beta$-HTBZ, it was predicted that the effect of a strong CYP2D6 inhibitor on these metabolites would be lower for deutetrabenazine than for tetrabenazine. Thus, in this study, the pharmacokinetic profiles of deutetrabenazine and its metabolites were assessed in the absence and presence of paroxetine, a potent CYP2D6 inhibitor. Paroxetine is commonly used in drug-drug interaction studies as a representative potent CYP2D6 inhibitor and is also a frequent concomitant medication in the intended patient population. The quantification of the impact with deuteration in exposure in patients with impaired CYP2D6 function was used, together with population pharmacokinetic modeling (data on file, Teva Pharmaceutical Industries, Ltd), to support appropriate dosing recommendations for deutetrabenazine for registration studies.

\section{Methods}

\section{Ethics}

The study was performed in accordance with Good Laboratory Practice and the International Conference on Harmonization Harmonized Tripartite Guideline regarding Good Clinical Practice. The study was conducted by Celerion in Tempe, Arizona, USA (Principal Investigator, Terry O'Reilly, MD, Certified Physician Investigator), and all study documents were reviewed by the Institutional Review Board, Chesapeake Research Review, Inc. The study protocol was designed by Auspex Pharmaceuticals (La Jolla, CA, USA), which was acquired by Teva Pharmaceutical Industries Ltd (Petah Tikva, Israel).

\section{Study participants}

This study included healthy male or female volunteers, between 18 and 50 years of age. Subjects were excluded if they were a CYP2D6 poor (null/null genotype) or ultra-rapid (3 or more wild type alleles) metabolizer. Other exclusion criteria were the use of tobacco or nicotine products in the previous 3 months, use of any over-the-counter medications, herbal or hormone supplements other than approved hormonal contraception, or diet aids within 14 days of start of dosing. Approved doses of acetaminophen or ibuprofen were not excluded.

\section{Study design}

This was an open-label sequential drug-drug interaction study in 24 healthy adult subjects who were CYP2D6 extensive metabolizers (EM) or CYP2D6 intermediate metabolizers (IM); Supplemental Table S1 provides the genotypes and phenotypes of the subjects. The genotype testing was performed by Genelex (Seattle, WA, USA) on a Luminex 100xMAP IS system using the xTAGCYP2D6 v2 assay kit (Luminex Molecular Diagnostics Inc, Toronto CA) which detects a panel of 17 small nucleotide variants found within the highly polymorphic cytochrome P450-2D6 gene located on chromosome 22, gene rearrangements associated with the deletion $(* 5)$ and duplication genotypes.

Subjects checked into the clinic on day 1 and were confined through day 14 . While confined in the clinic, subjects were given frequent safety assessments, including adverse event reporting, ECG recordings, and physical and laboratory examinations including the Columbia Suicide Severity rating scale (C-SSRS), an FDA-mandated questionnaire to screen for suicidality in trials of CNS active compounds [10]. Those who met inclusion/exclusion criteria received a single dose of deutetrabenazine on day 1 followed by a 72-h washout. Subjects then received paroxetine on days 4 to 12 to achieve steady-state plasma concentrations of paroxetine by day 11 . On day 11 , another single dose of deutetrabenazine was administered. Triplicate 12-lead digital electrocardiograms (ECGs) were collected predose and for $10 \mathrm{~h}$ following deutetrabenazine dosing on day 1 , and for $10 \mathrm{~h}$ on day 11 , following paroxetine administration on day 10. Blood samples for measurement of plasma concentrations of deutetrabenazine and its metabolites were obtained on days 1 and 11 (predose, 1, 2, 2.5, 3, 3.5, 4, $4.5,5,6,7,8,10,12$, and $16 \mathrm{~h}$ ), days 2 and 12 , at 24 and $36 \mathrm{~h}$, days 3 and 13 , at 48 and $60 \mathrm{~h}$ and days 4 and 14 , at $72 \mathrm{~h}$. Paroxetine trough levels were obtained pre-dose on days $9,10,11$, and 12 , and on day 13 at $24 \mathrm{~h}$ post the final paroxetine dose on day 12. Blood and urine samples were collected for clinical laboratory testing (hematology, serum chemistries, and urinalysis) at admission and after at least $10 \mathrm{~h}$ fasting and at study completion on day 14 or upon early withdrawal. 


\section{Treatments}

All participants received the following treatments, deutetrabenazine $22.5-\mathrm{mg}$ oral dose as one $15-\mathrm{mg}$ tablet + one $7.5-\mathrm{mg}$ tablet on days 1 and 11 and one paroxetine $20 \mathrm{mg}$ (Cadila Healthcare Ltd.) oral tablet on days 4 through 12 . The deutetrabenazine $22.5-\mathrm{mg}$ dose was administered with $237 \mathrm{~mL}$ of water in the morning approximately $30 \mathrm{~min}$ after a standardized breakfast meal with moderate fat content (35\%). No food was allowed for at least $4 \mathrm{~h}$ postdose, and subjects were asked to remain upright for at least $4 \mathrm{~h}$ postdose, unless medically necessary.

Paroxetine $20 \mathrm{mg}$ was administered in the morning with $237 \mathrm{~mL}$ water for 9 days (days 4 to 12 ) to ensure steadystate levels. On days 4 to 10 and 12, the paroxetine dose was administered in a fed state $30 \mathrm{~min}$ after breakfast. On day 11 , as paroxetine can be administered without regard to food [11], subjects took the paroxetine dose under fasting conditions (at least $1 \mathrm{~h}$ prior to breakfast and $1.5 \mathrm{~h}$ prior to deutetrabenazine administration) following an overnight fast of at least $10 \mathrm{~h}$. Subjects were asked to remain upright for at least $1 \mathrm{~h}$ after the paroxetine dose, unless medically necessary.

\section{Bioanalytical measures}

Validated liquid chromatography/tandem mass spectrometry methods were applied to assess plasma concentrations of paroxetine, deutetrabenazine, $\alpha$ - and $\beta$-HTBZ metabolites, and the O-desmethyl metabolites of $\alpha$ - and $\beta$-HTBZ. This was performed on a Sciex API 4000 instrument, equipped with a Turbo Ion Spray ion source operated in the positive ion mode and interfaced to a Shimadzu HPLC system fitted with a Waters XBridge $\mathrm{C}_{18}$ reverse phase column $(3.5 \mu \mathrm{m}$; $50 \times 2.1 \mathrm{~mm}$ ) for paroxetine, deutetrabenazine, $\alpha-\mathrm{HTBZ}$ and $\beta$-HTBZ or a Phenomenex Kinetex column $(2.6 \mu \mathrm{m}$; $100 \times 2.1 \mathrm{~mm}$ ) for the O-desmethyl metabolites. The validated assay ranges were as follows: paroxetine 0.500 to $50.0 \mathrm{ng} /$ $\mathrm{mL}$, deutetrabenazine 0.100 to $10.0 \mathrm{ng} / \mathrm{mL}$, deuterated $\alpha$ - and $\beta$-HTBZ 0.500 to $100 \mathrm{ng} / \mathrm{mL}$, and 9-O- and 10-O-desmethyl metabolites of $\alpha-\mathrm{HTBZ}$ and $\beta$-HTBZ 0.5 to $50.0 \mathrm{ng} / \mathrm{mL}$. The methods were developed and validated by CPR Pharma Services, Pty, Ltd Australia, as described earlier [5].

\section{Pharmacokinetic analyses}

Plasma concentrations, below the limit of quantitation (BLQ) of the assay, were designated a value of zero for initial and time points occurring at the end of the profile. For sampling time points between two quantifiable concentrations, plasma concentrations BLQ followed by a measurable concentration were set to the limit of quantitation of the assay. Total deuterated $(\alpha+\beta)$-HTBZ was calculated as the sum of the $\alpha$ - and $\beta$-HTBZ metabolites. The imputed value was used for calculation of total deuterated $(\alpha+\beta)$-HTBZ, for calculation of descriptive summary statistics, in determination of PK parameters, and for presentation in the individual profiles. The PK parameters were determined using Phoenix WinNonlin, Version 6.3 (Pharsight Corporation). PK parameters included the following: area under the plasma concentration-time curve from time 0 to the time of the last quantifiable concentration $\left(\mathrm{AUC}_{0-t}\right)$, area under the plasma concentrationtime curve from time 0 to infinity $\left(\mathrm{AUC}_{0-\infty}\right)$, maximum observed plasma drug concentration $\left(\mathrm{C}_{\max }\right)$, time to $\mathrm{C}_{\max }\left(\mathrm{T}_{\max }\right)$, terminal elimination half-life $\left(t_{1 / 2}\right)$, terminal elimination rate constant $\left(\lambda_{\mathrm{Z}}\right)$, percentage of $\mathrm{AUC}_{0-\infty}$ extrapolated (\% $\left.\mathrm{AUC}_{\text {extrap }}\right)$, apparent total body clearance $(\mathrm{CL} / F)$, and apparent volume of distribution $\left(V_{z} / F\right)$.

\section{Statistical analysis}

No formal sample size calculation was performed. The sample size was selected based on the magnitude of effect observed in a previous study looking at the effect of paroxetine on the pharmacokinetic of tetrabenazine, where a threefold increase in the exposure of $\alpha-\mathrm{HTBZ}$ and a ninefold increase in the exposure of $\beta$-HTBZ were observed [7]. It was anticipated that 24 subjects would be sufficient to characterize this effect and allow recommendations on doses of deutetrabenazine to be used in combination with CYP2D6 inhibitors.

The effect of paroxetine on the pharmacokinetics of deutetrabenazine was assessed using two-sided $90 \%$ confidence intervals (CIs) for the differences between log-transformed values of the parameters $\mathrm{C}_{\max }, \mathrm{AUC}_{0-t}$, and $\mathrm{AUC}_{0-\infty}$. Confidence intervals $(90 \%)$ were constructed for the treatment ratios (deutetrabenazine + paroxetine to deutetrabenazine alone) of $\mathrm{C}_{\max }, \mathrm{AUC}_{0-t}$, and $\mathrm{AUC}_{0-\infty}$ for $\alpha-\mathrm{HTBZ}, \beta-\mathrm{HTBZ}$, and total $(\alpha+\beta)$-HTBZ and O-desmethyl HTBZ metabolites as required using the log-transformed data. The point estimates and confidence limits were back-transformed to the original scale. The attainment of steady state with respect to paroxetine was assessed by comparing the predose plasma concentrations on treatment days 9, 10, 11, 12, and 13 (24 $\mathrm{h}$ after the final paroxetine dose on day 12) graphically. Descriptive statistics were calculated for plasma concentration-time profiles and pharmacokinetic parameters.

\section{Results}

\section{Subject disposition and demographics}

All 24 enrolled subjects (16 EM and 8 IM participants) completed the study. One subject could not be correctly classified 
regarding his CYP2D6 metabolizer status because of multiple copies of one of the alleles which could be classified as an ultra-metabolizer, meeting an exclusion criterion and thus was excluded from the primary PK analysis population; however, his data were included in a secondary analysis of bioavailability. The mean (SD) age of participants was 31.6 (9.8) years, and mean (SD) weight was $70.5(11.3) \mathrm{kg} ; 33 \%$ were female, and 96\% were white, and 1 (4\%) was black or African American.

\section{Safety}

Single doses of $22.5 \mathrm{mg}$ deutetrabenazine, when given alone or in the presence of steady-state paroxetine ( $20 \mathrm{mg}$ daily), were safe and generally well tolerated in healthy subjects. There were no deaths, serious adverse events, cardiac safety events, suicidal behavior (based on C-SSRS), or discontinuations due to adverse events. A summary of the proportion of subjects experiencing AEs is presented in Supplemental Table S2. Most TEAEs were mild in severity and resolved without sequelae. All mean ECG parameters (HR, PR, QRS, RR, QTc, and T-wave amplitude) remained within normal limits, with QTcF mean intervals remaining $<410 \mathrm{~ms}$ following all treatments.

\section{Pharmacokinetic evaluations}

Steady-state exposure of the strong CYP2D6 inhibitor paroxetine was achieved on day 10 as confirmed by visual inspection of the mean trough plasma concentrations. The mean plasma concentrations of deutetrabenazine and the active metabolites ( $\alpha$-HTBZ, $\beta$-HTBZ, and total $(\alpha+\beta)$-HTBZ) in the absence (day 1) and presence (day 11) of steady-state concentrations of paroxetine are presented in Fig. 1. The parent drug deutetrabenazine appeared only transiently in plasma, and its concentrations were remarkably lower than concentrations of the deuterated active metabolites. Mean plasma concentrations of deutetrabenazine in the presence and absence of paroxetine were comparable. Mean plasma concentrations of the active metabolites $\alpha$-HTBZ and $\beta$-HTBZ individually and in total were higher in the presence of paroxetine compared to the same subjects receiving deutetrabenazine alone.

Key PK parameters of the parent drug and the deuterated active metabolites in the absence and presence of paroxetine, overall and by phenotype (EM or IM), are provided in Table 1. The strong CYP2D6 inhibitor paroxetine increased $\mathrm{C}_{\max }$ and total exposure ( $\mathrm{AUC}_{0-\infty}$ ) of both metabolites. The increased exposure was associated with an increased halflife $\left(t_{1 / 2}\right)$ of both active metabolites with a stronger effect on $\beta$-HTBZ (2.7-fold) versus $\alpha$-HTBZ (1.5-fold). The extent of increase in presence of paroxetine was higher for $\beta$-HTBZ (2.1-fold for $\mathrm{C}_{\max }$ and 5.6-fold for $\mathrm{AUC}_{0-\infty}$ ) compared to $\alpha$-HTBZ (1.2-fold for $\mathrm{C}_{\max }$ and 1.8-fold for $\mathrm{AUC}_{0-\infty}$ ) and higher for total exposure versus maximum exposure. The higher exposure of the individual metabolites led to an about 1.6-fold higher $\mathrm{C}_{\max }$ and threefold higher $\mathrm{AUC}_{0-\infty}$ for total $(\alpha+\beta)$-HTBZ in a population of $15 \mathrm{EM}$ and $8 \mathrm{IM}$ (Fig. 2). The effect of paroxetine was observed to be greater in EM phenotype subjects compared with subjects with IM
Fig. 1 Mean plasma concentrations of deutetrabenazine and primary metabolites in the absence (dose day 1) and presence (dose day 11) of paroxetine. Deutetrabenazine $22.5 \mathrm{mg}$ was orally administered on days 1 and 11. Paroxetine $20 \mathrm{mg}$ was orally administered on days 4-12. Plasma sampling for assessment of deutetrabenazine and $\alpha$-HTBZ and $\beta$-HTBZ concentrations occurred for $72 \mathrm{~h}$ after each dose. HTBZ dihydrotetrabenazine

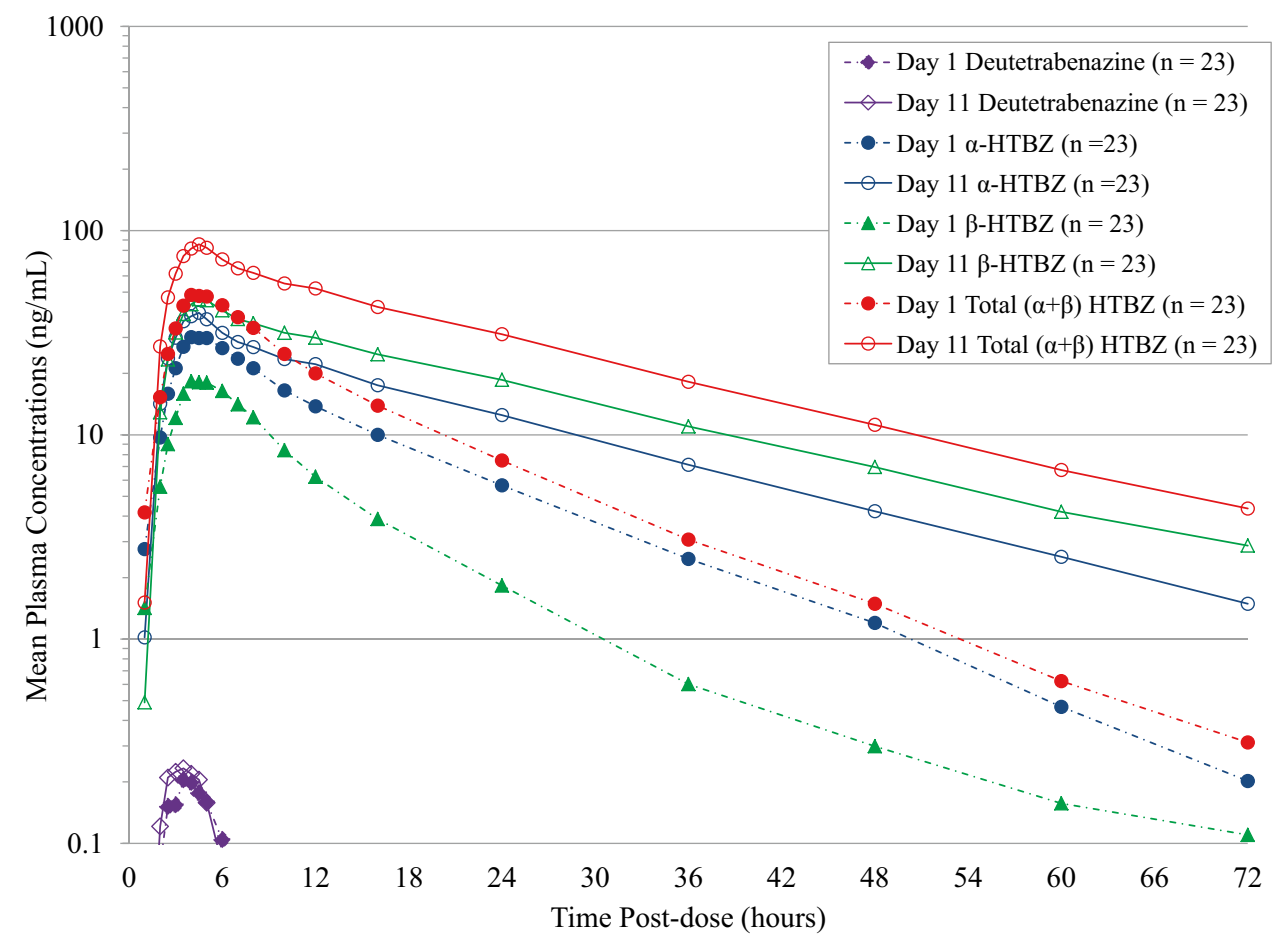


Table 1 Summary of key pharmacokinetic parameters of primary analytes by dose day and CYP2D6 phenotype

\begin{tabular}{|c|c|c|c|c|c|c|}
\hline \multirow{2}{*}{$\begin{array}{l}\text { Day } 1=\text { deutetrabenazine alone } \\
\text { Day } 11=\text { deutetrabenazine }+ \\
\text { Paroxetine } \\
\text { Mean }(\mathrm{CV} \%)\end{array}$} & \multicolumn{2}{|l|}{$\begin{array}{l}\text { All Subjects } \\
(n=23)\end{array}$} & \multicolumn{2}{|c|}{$\begin{array}{l}\text { Subjects with phenotype EM } \\
(n=15)\end{array}$} & \multicolumn{2}{|c|}{$\begin{array}{l}\text { Subjects with phenotype IM } \\
(n=8)\end{array}$} \\
\hline & Dose day 1 & Dose day 11 & Dose day 1 & Dose day 11 & Dose day 1 & Dose day 11 \\
\hline \multicolumn{7}{|l|}{ Deutetrabenazine } \\
\hline $\mathrm{C}_{\max }(\mathrm{ng} / \mathrm{mL})$ & $0.4(60)$ & $0.4(53)$ & $0.3(44)$ & $0.4(57)$ & $0.5(66)$ & $0.4(49)$ \\
\hline $\mathrm{T}_{\max }(\mathrm{h})^{\mathrm{a}}$ & $\begin{array}{l}3.5 \\
(1.0-6.0)\end{array}$ & $\begin{array}{l}3.0 \\
(2.0-4.5)\end{array}$ & $\begin{array}{l}3.5 \\
(1.0-6.0)\end{array}$ & $\begin{array}{l}3.0 \\
(2.0-4.5)\end{array}$ & $\begin{array}{l}3.5 \\
(1.0-6.0)\end{array}$ & $\begin{array}{l}3.3 \\
(2.0-4.5)\end{array}$ \\
\hline $\mathrm{AUC}_{0-\mathrm{t}}(\mathrm{ng} \times \mathrm{h} / \mathrm{mL})$ & $0.8(53)$ & $0.8(60)$ & $0.6(40)$ & $0.7(67)$ & $1.0(55)$ & $1.0(50)$ \\
\hline $\begin{array}{l}t_{1 / 2}(\mathrm{~h})^{\mathrm{b}} \\
\alpha-\mathrm{HTBZ}\end{array}$ & $\mathrm{NC}$ & $\mathrm{NC}$ & $\mathrm{NC}$ & $\mathrm{NC}$ & $\mathrm{NC}$ & $\mathrm{NC}$ \\
\hline $\mathrm{C}_{\max }(\mathrm{ng} / \mathrm{mL})$ & $37.4(22)$ & $45.4(25)$ & $35.8(21)$ & $46.6(27)$ & $40.5(22)$ & $43.2(21)$ \\
\hline $\mathrm{T}_{\max }(\mathrm{h})^{\mathrm{a}}$ & $\begin{array}{l}4.0 \\
(2.0-7.0)\end{array}$ & $\begin{array}{l}3.5 \\
(2.0-5.0)\end{array}$ & $\begin{array}{l}4.0 \\
(2.0-6.0)\end{array}$ & $\begin{array}{l}3.5 \\
(2.0-4.5)\end{array}$ & $\begin{array}{l}4.0 \\
(2.0-7.0)\end{array}$ & $\begin{array}{l}3.5 \\
(2.5-5.0)\end{array}$ \\
\hline $\mathrm{AUC}_{0-\infty}(\mathrm{ng} \times \mathrm{h} / \mathrm{mL})$ & $427(34)$ & $780(28)$ & $363(31)$ & $706(29)$ & $546(22)$ & $921(18)$ \\
\hline$t_{1 / 2}(\mathrm{~h})$ & $10.5(28)$ & $15.5(18)$ & $9.1(20)$ & $14.0(14)$ & $13.0(23)$ & $18.1(11)$ \\
\hline \multicolumn{7}{|l|}{$\beta$-HTBZ } \\
\hline $\mathrm{C}_{\max }(\mathrm{ng} / \mathrm{mL})$ & $24.6(38)$ & $51.5(25)$ & $20.4(33)$ & $52.0(28)$ & $32.6(22)$ & $50.5(21)$ \\
\hline $\mathrm{T}_{\max }(\mathrm{h})^{\mathrm{a}}$ & $\begin{array}{l}4.01 \\
(2.0-8.0)\end{array}$ & $\begin{array}{l}3.6 \\
(2.0-6.0)\end{array}$ & $\begin{array}{l}4.0 \\
(2.0-6.0)\end{array}$ & $\begin{array}{l}3.5 \\
(2.0-5.0)\end{array}$ & $\begin{array}{l}4.0 \\
(2.0-8.0)\end{array}$ & $\begin{array}{l}4.3 \\
(3.5-6.0)\end{array}$ \\
\hline $\mathrm{AUC}_{0-\infty}(\mathrm{ng} * \mathrm{~h} / \mathrm{mL})$ & $199(90)$ & $1121(40)$ & $128(46)$ & $916(40)$ & $333(75)$ & $1507(20)$ \\
\hline$t_{1 / 2}(\mathrm{~h})$ & $5.9(48)$ & $16.2(28)$ & $4.8(24)$ & $13.7(19)$ & $7.9(50)$ & $21.1(15)$ \\
\hline \multicolumn{7}{|l|}{ Total $(\alpha+\beta)$ HTBZ } \\
\hline $\mathrm{C}_{\max }(\mathrm{ng} / \mathrm{mL})$ & $61.8(26)$ & $95.9(25)$ & $56.0(25)$ & $97.8(27)$ & $72.8(19)$ & $92.2(21)$ \\
\hline $\mathrm{T}_{\max }(\mathrm{h})^{\mathrm{a}}$ & $\begin{array}{l}4.0 \\
(2.0-8.0)\end{array}$ & $\begin{array}{l}3.6 \\
(2.0-6.0)\end{array}$ & $\begin{array}{l}4.0 \\
(2.0-8.0)\end{array}$ & $\begin{array}{l}3.5 \\
(2.0-5.0)\end{array}$ & $\begin{array}{l}4.3 \\
(2.0-8.0)\end{array}$ & $\begin{array}{l}4.3 \\
(2.5-6.0)\end{array}$ \\
\hline $\mathrm{AUC}_{0-\infty}(\mathrm{ng} * \mathrm{~h} / \mathrm{mL})$ & $624(49)$ & $1901(34)$ & $489(35)$ & $1622(35)$ & $874(39)$ & $2423(19)$ \\
\hline$t_{1 / 2}(\mathrm{~h})$ & $9.8(28)$ & $16.0(24)$ & $8.6(23)$ & $14.1(20)$ & $12.0(23)$ & $19.8(13)$ \\
\hline
\end{tabular}

$N C$ not calculated, $A U C_{0-\infty}$ the area under the plasma concentration versus time curve from time 0 extrapolated to infinity, $C_{\max }$ maximum plasma concentration; $C V$ coefficient of variation, $E M$ extensive metabolizer, $H T B Z$ dihydrotetrabenazine, $I M$ intermediate metabolizer, $t_{I / 2}$ half-life, $T_{\max }$ maximum plasma concentration

${ }^{a}$ Median (min-max)

${ }^{\mathrm{b}}$ Half-life could not be calculated for the parent drug, deutetrabenazine because the terminal elimination rate constant could not be determined phenotype. In comparison to EM, the observed changes in IM were about 30 and $20 \%$ lower for $\mathrm{C}_{\max }$ and $\mathrm{AUC}_{0-\infty}$, respectively. For comparisons of $\mathrm{C}_{\max }, \mathrm{AUC}_{0-t}$, and $\mathrm{AUC}$ $0-\infty$ in the presence and absence of paroxetine, \% ratios of LS means and corresponding 90\% confidence intervals are provided in Table 2.

Prolongation of the half-lives of $\alpha$-HTBZ and $\beta$-HTBZ in the presence of paroxetine was associated with reduced production of O-desmethyl metabolites of HTBZ. Briefly, 9-O-desmethyl $\alpha$ - and $\beta$-HTBZ were quantifiable throughout the time course while $10-\mathrm{O}$-desmethyl $\alpha$-HTBZ was below the lower limit of quantitation on all-time points and 10-O-desmethyl $\beta$-HTBZ appeared transiently in some subjects in the absence of paroxetine and was below the lower limit of quantitation in the presence of paroxetine indicating a reduced formation of this metabolite. PK parameters of 9-O-desmethyl $\alpha$-HTBZ and 9-O-desmethyl $\beta$-HTBZ are displayed in Table 3 . In the overall population, $\mathrm{AUC}_{0-\mathrm{t}}$ and $\mathrm{C}_{\text {max }}$ were lower by a factor of 0.3 and 0.4 for 9-O-desmethyl $\alpha$-HTBZ and 0.7 and 0.4 for 9-O-desmethyl $\beta$-HTBZ, respectively.

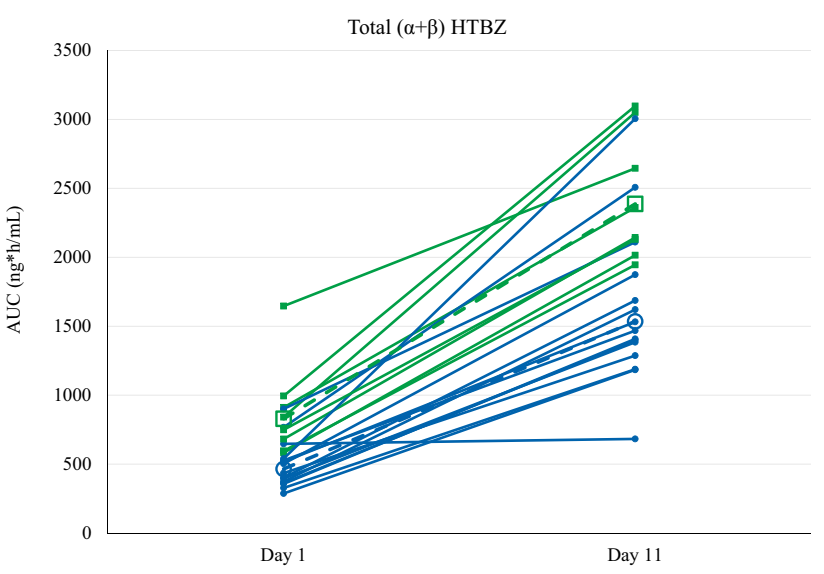

Fig. 2 Individual $\mathrm{AUC}_{0-\infty}(\mathrm{ng} \times \mathrm{h} / \mathrm{mL})$ values for each subject for total $(\alpha+\beta)$ dihydrotetrabenazine following deutetrabenazine dosing in the absence (dose day 1) and presence (dose day 11) of paroxetine. Deutetrabenazine $22.5 \mathrm{mg}$ was orally administered on days 1 and 11. Paroxetine $20 \mathrm{mg}$ was orally administered on days $4-12$. $\mathrm{AUC}_{0-\infty}$ values for subjects with CYP2D6 extensive metabolizer phenotype are shown as filled blue circles and blue lines; geometric mean is shown as an open circle with a dashed blue line. AUC values for subjects with CYP2D6 intermediate metabolizer phenotype are shown as filled green squares with green lines; geometric mean is shown as an open square with a dashed green line 
Table 2 Comparison of pharmacokinetic parameters by analytes for deutetrabenazine administration with and without paroxetine administration

\begin{tabular}{|c|c|c|c|c|}
\hline \multicolumn{2}{|c|}{$\begin{array}{l}\text { Day } 1=\text { deutetrabenazine alone } \\
\text { Day } 11=\text { deutetrabenazine }+ \text { paroxetine }\end{array}$} & \multicolumn{3}{|c|}{$\begin{array}{l}\text { \% Ratio of LS means }(90 \% \text { CI) } \\
\text { (day 11)/(day 1) }\end{array}$} \\
\hline & & $\begin{array}{l}\text { Subjects with EM } \\
\text { phenotype } \\
(n=15)\end{array}$ & $\begin{array}{l}\text { Subjects with } \\
\text { IM phenotype } \\
(n=8)\end{array}$ & $\begin{array}{l}\text { All subjects } \\
(n=23)\end{array}$ \\
\hline \multirow[t]{3}{*}{$\alpha-\mathrm{HTBZ}$} & $\mathrm{C}_{\max }(\mathrm{ng} / \mathrm{mL})$ & $\begin{array}{l}119.9 \\
(108.1-132.9)\end{array}$ & $\begin{array}{l}127.8 \\
(111.8-146.1)\end{array}$ & $\begin{array}{l}106.3 \\
(90.0-125.4)\end{array}$ \\
\hline & $\mathrm{AUC}_{0-\mathrm{t}}(\mathrm{ng} \times \mathrm{h} / \mathrm{mL})$ & $\begin{array}{l}181.6 \\
(162.4-302.0)\end{array}$ & $\begin{array}{l}192.2 \\
(162.9-226.8)\end{array}$ & $\begin{array}{l}163.3 \\
(148.3-179.8)\end{array}$ \\
\hline & $\mathrm{AUC}_{0-\infty}(\mathrm{ng} \times \mathrm{h} / \mathrm{mL})$ & $\begin{array}{l}185.0 \\
(165.8-206.4)\end{array}$ & $\begin{array}{l}193.6 \\
(164.4-228.0)\end{array}$ & $\begin{array}{l}169.8 \\
(153.8-187.5)\end{array}$ \\
\hline \multirow[t]{3}{*}{$\beta$-HTBZ } & $\mathrm{C}_{\max }(\mathrm{ng} / \mathrm{mL})$ & $\begin{array}{l}216.4 \\
(185.0-253.2)\end{array}$ & $\begin{array}{l}259.2 \\
(216.7-310.1)\end{array}$ & $\begin{array}{l}154.3 \\
(126.0-189.0)\end{array}$ \\
\hline & $\mathrm{AUC}_{0-\mathrm{t}}(\mathrm{ng} \times \mathrm{h} / \mathrm{mL})$ & $\begin{array}{l}641.3 \\
(537.3-765.4)\end{array}$ & $\begin{array}{l}744.6 \\
(605.3-915.8)\end{array}$ & $\begin{array}{l}484.7 \\
(355.2-661.5)\end{array}$ \\
\hline & $\mathrm{AUC}_{0-\infty}(\mathrm{ng} \times \mathrm{h} / \mathrm{mL})$ & $\begin{array}{l}649.9 \\
(549.6-768.5)\end{array}$ & $\begin{array}{l}731.5 \\
(595.0-899.3)\end{array}$ & $\begin{array}{l}520.6 \\
(388.9-697.0)\end{array}$ \\
\hline \multirow[t]{3}{*}{ Total $(\alpha+\beta)$-HTBZ } & $\mathrm{C}_{\max }(\mathrm{ng} / \mathrm{mL})$ & $\begin{array}{l}154.8 \\
(137.4-174.4)\end{array}$ & $\begin{array}{l}173.1 \\
(149.8-200.1)\end{array}$ & $\begin{array}{l}125.6 \\
(105.4-149.6)\end{array}$ \\
\hline & $\mathrm{AUC}_{0-\mathrm{t}}(\mathrm{ng} \times \mathrm{h} / \mathrm{mL})$ & $\begin{array}{l}303.6 \\
(268.0-343.8)\end{array}$ & $\begin{array}{l}324.9 \\
(273.9-385.4)\end{array}$ & $\begin{array}{l}267.3 \\
(224.0-318.9)\end{array}$ \\
\hline & $\mathrm{AUC}_{0-\infty}(\mathrm{ng} \times \mathrm{h} / \mathrm{mL})$ & $\begin{array}{l}314.7 \\
(278.4-355.6)\end{array}$ & $\begin{array}{l}329.8 \\
(277.7-391.8)\end{array}$ & $\begin{array}{l}288.1 \\
(242.3-342.5)\end{array}$ \\
\hline
\end{tabular}

$C_{\text {max }}$ maximum plasma concentration, $A U C_{0-t}$ area under concentration-time curve from time 0 to time of the last quantifiable concentration, $A U C_{0-\infty}$ the area under the plasma concentration versus time curve from time 0 extrapolated to infinity, $H T B Z$ dihydrotetrabenazine, $L S$ means $(90 \% \mathrm{CI})$ least-square means with $90 \%$ confidence intervals, $E M$ extensive metabolizer, $I M$ intermediate metabolizer

Table 3 Summary of key pharmacokinetic parameters of 9-O-desmethyl HTBZ metabolites overall and by CYP2D6 phenotype

\begin{tabular}{|c|c|c|c|c|c|c|}
\hline \multirow{2}{*}{$\begin{array}{l}\text { Dose day } 1=\text { Deutetrabenazine alone } \\
\text { Dose day } 11=\text { Deutetrabenazine }+ \\
\text { paroxetine } \\
\text { Mean }(\mathrm{CV} \%)\end{array}$} & \multicolumn{2}{|c|}{$\begin{array}{l}\text { All participants } \\
(n=23)^{\mathrm{a}}\end{array}$} & \multicolumn{2}{|c|}{$\begin{array}{l}\text { Subjects with phenotype EM } \\
(n=15)^{\mathrm{b}}\end{array}$} & \multicolumn{2}{|c|}{$\begin{array}{l}\text { Subjects with phenotype IM } \\
(n=8)^{\mathrm{c}}\end{array}$} \\
\hline & $\begin{array}{l}\text { Dose } \\
\text { day } 1\end{array}$ & $\begin{array}{l}\text { Dose } \\
\text { day } 11\end{array}$ & $\begin{array}{l}\text { Dose } \\
\text { day } 1\end{array}$ & $\begin{array}{l}\text { Dose } \\
\text { day } 11\end{array}$ & Dose day 1 & Dose day 11 \\
\hline \multicolumn{7}{|l|}{ 9-O-desmethyl $\alpha$-HTBZ } \\
\hline $\mathrm{C}_{\max }(\mathrm{ng} / \mathrm{mL})$ & $1.3(28)$ & $0.5(73)$ & $1.4(18)$ & $0.5(57)$ & $1.2(45)$ & $0.4(112)$ \\
\hline $\mathrm{T}_{\max }(\mathrm{h})^{\mathrm{d}}$ & $\begin{array}{l}5.0 \\
(3.0-12.0)\end{array}$ & $\begin{array}{l}4.5 \\
(3.5-24.1) \\
(n=16)\end{array}$ & $\begin{array}{l}5.0 \\
(3.0-8.0)\end{array}$ & $\begin{array}{l}4.5 \\
(3.5-10.0) \\
(n=12)\end{array}$ & $\begin{array}{l}5.5 \\
(3.5-12.0)\end{array}$ & $\begin{array}{l}4.3 \\
(4.0-24.1) \\
(n=4)\end{array}$ \\
\hline $\mathrm{AUC}_{0-\mathrm{t}}(\mathrm{ng} \times \mathrm{h} / \mathrm{mL})$ & $13.9(48)$ & $4.6(128)$ & $13.9(39)$ & $4.3(122)$ & $13.8(65)$ & $5.1(144)$ \\
\hline$t_{1 / 2}(\mathrm{~h})$ & $\mathrm{NC}$ & $\mathrm{NC}$ & $\mathrm{NC}$ & $\mathrm{NC}$ & $\mathrm{NC}$ & $\mathrm{NC}$ \\
\hline \multicolumn{7}{|l|}{ 9-O-desmethyl $\beta$-HTBZ } \\
\hline $\mathrm{C}_{\max }(\mathrm{ng} / \mathrm{mL})$ & $4.4(29)$ & $1.6(36)$ & $4.5(20)$ & $1.6(31)$ & $4.2(45)$ & $1.6(47)$ \\
\hline $\mathrm{T}_{\max }(\mathrm{h})^{\mathrm{a}}$ & $\begin{array}{l}6.0 \\
(2.5-24.0)\end{array}$ & $\begin{array}{l}16.0 \\
(4.5-24.1)\end{array}$ & $\begin{array}{l}5.0 \\
(2.5-8.0)\end{array}$ & $\begin{array}{l}16.0 \\
(10.0-24.1)\end{array}$ & $\begin{array}{l}7.0 \\
(4.0-24.0)\end{array}$ & $\begin{array}{l}24.0 \\
(4.5-24.1)\end{array}$ \\
\hline $\mathrm{AUC}_{0-\mathrm{t}}(\mathrm{ng} \times \mathrm{h} / \mathrm{mL})$ & $92.0(32)$ & $68.4(37)$ & $85.1(28)$ & $66.7(38)$ & $105(33)$ & $73.5(36)$ \\
\hline$t_{1 / 2}(\mathrm{~h})$ & $\begin{array}{l}16.2(14) \\
(n=21)\end{array}$ & $\begin{array}{l}24.5(12) \\
(n=10)\end{array}$ & $15.9(15)(n=14)$ & $\begin{array}{l}23.8(12) \\
(n=8)\end{array}$ & $\begin{array}{l}16.8(13) \\
(n=7)\end{array}$ & $\begin{array}{l}27.4(9) \\
(n=2)\end{array}$ \\
\hline
\end{tabular}

$\mathrm{AUC}_{0-t}$ area under the plasma concentration-time curve from time 0 to the time of the last quantifiable concentration, $\mathrm{C}_{\max }$ maximum plasma concentration, CV coefficient of variation, EM extensive metabolizer, HTBZ dihydrotetrabenazine, IM intermediate metabolizer, NC not calculable, $t_{1 / 2}$ half-life, $t_{\max }$ time of maximum plasma concentration

${ }^{\mathrm{a}} n=23$, except where indicated

${ }^{\mathrm{b}} n=15$ except where indicated

${ }^{c} n=8$ except where indicated

${ }^{\mathrm{d}}$ Median (min-max) 


\section{Discussion}

Deutetrabenazine was rationally designed using the process of deuteration with the intent of slowing the CYP2D6dependent breakdown of the active metabolites of tetrabenazine to their less potent O-desmethyl metabolites. Earlier studies confirmed that deutetrabenazine tablets administered with food can provide the desired overall exposure and a lower $\mathrm{C}_{\max }$ with half the dose of tetrabenazine $[5,6]$ and a linear PK of the active metabolites. The study described herein investigated the effect of the strong CYP2D6 inhibitor paroxetine on the pharmacokinetics and safety of a single dose of deutetrabenazine.

Paroxetine administered with tetrabenazine increased $\mathrm{C}_{\max }$ by 1.3- and threefold and AUC by 2.4- and ninefold for $\alpha-\mathrm{HTBZ}$ and $\beta$-HTBZ, respectively [7, 9]. Based on these findings, it is recommended that patients who take strong CYP2D6 inhibitors and or CYP2D6 poor metabolizers (PM) limit their daily tetrabenazine intake to $50 \mathrm{mg}, 50 \%$ of the maximum allowed daily dose (100 $\mathrm{mg})[7,9]$.

Deuterated $\alpha$-HTBZ and $\beta$-HTBZ, the metabolites of deutetrabenazine, are also metabolized by CYP2D6 but at a lower rate [5]. Therefore, a weaker effect of the strong CYP2D6 inhibitor paroxetine on the CYP2D6 catalyzed metabolism would be expected, and indeed was confirmed in the present study for both active deuterated metabolites with a resultant increase for $\alpha-\mathrm{HTBZ}$ of 1.2 -fold for $\mathrm{C}_{\max }$ and 1.8-fold for $\mathrm{AUC}_{0-\infty}$, and for $\beta$-HTBZ of 2.1-fold for $\mathrm{C}_{\max }$ and 5.6-fold for $\mathrm{AUC}_{0-\infty}$. The higher effect of impaired CYP2D6 functions on $\beta$-HTBZ compared to $\alpha$-HTBZ is consistent for deutetrabenazine and tetrabenazine and suggests that $\alpha$-HTBZ is not exclusively metabolized by CYP2D6. The reduced exposure to O-desmethyl metabolites of deuterated $\alpha$-HTBZ and $\beta$-HTBZ confirmed the effect of the strong CYP2D6 inhibitor on the demethylation of $\alpha$-HTBZ and $\beta$-HTBZ, which is catalyzed by CYP2D6.

Although there was considerable overlap in individual subjects, the effect of paroxetine was observed to be greater in subjects with extensive CYP2D6 metabolizer (EM) phenotype than those with and intermediate (IM) phenotype for both $\mathrm{C}_{\max }$ and AUC. However, the minor differences between EM and IM do not demand a different dosing scheme for these populations. Maximum exposure to $\alpha$-HTBZ and $\beta$-HTBZ is slightly higher in IM compared to $\mathrm{EM}$ in the absence of paroxetine but comparable between $\mathrm{IM}$ and EM in the presence of the inhibitor.

One of the limitations of the present study was that CYP2D6 poor metabolizer (PM) phenotype was not investigated. However, the effect of paroxetine has been shown to shift the CYP2D6 phenotype from EM to PM $[12,13]$, although not necessarily in $100 \%$ of those treated subjects [14]. Thus, the dose recommendations for those taking strong CYP2D6 inhibitors apply to PM as well. Conversely, the ultrametabolizer (UM) phenotype was also not assessed; however, the results by Laine et al. 2001 suggest that there are no safety concerns and that use of paroxetine would normalize the UM phenotype [15].

Safety data including ECG assessments did not indicate increased risk for side effects in the presence of a strong inhibitor at the tested dose. In previous clinical safety and efficacy studies, deutetrabenazine showed a favorable side effect profile that is overall similar to placebo [16]. These data are consistent with the moderate increase in maximum exposure and the generally lower $\mathrm{C}_{\max }$ of the deuterated drug compared to the non-deuterated from previous reports [5, 6]. Although paroxetine substantially increased $\alpha$-HTBZ and $\beta$-HTBZ exposure after administration of deutetrabenazine, the magnitude of the effect was less than that observed for tetrabenazine in a study with a similar design $[7,9]$. Thus, these results indicate that deuteration reduces the impact of concomitant use of a strong CYP2D6 inhibitor on $\alpha$-HTBZ and $\beta$-HTBZ exposure.

The information on the effects of impaired CYP2D6 metabolism of deutetrabenazine from this study together with the data from PK comparisons to tetrabenazine [5, 6] and population PK analyses (data on file, Teva Pharmaceutical Industries Ltd) were used to establish the doses in the phase 3 efficacy and safety studies which supported registration of deutetrabenazine (Austedo) as a treatment for chorea for Huntington's disease and tardive dyskinesia $[1,3,4]$. Accordingly, the maximum recommended deutetrabenazine dose for patients with Huntington's disease or tardive dyskinesia who have impaired CYP2D6 function (PM or taking strong CYP2D6 inhibitors) is $36 \mathrm{mg} /$ day (18 $\mathrm{mg}$ BID), a $25 \%$ reduction in the maximum recommended dose for patients with normal CYP2D6 function, $48 \mathrm{mg} /$ day (24 mg BID).

Supplementary information The online version contains supplementary material available at https://doi.org/10.1007/s00228-021-03202-0.

Author contribution DS and MJB designed and performed the study. FS, PSL, DS, MJB, MFG, and LRG analyzed and interpreted the results. FS and PSL wrote the manuscript. DS, MB, MFG, and LRG reviewed the manuscript and provided substantive comments.

Funding The studies described in this report were sponsored by Auspex Pharmaceuticals, Inc. (La Jolla, CA) which was acquired by Teva Pharmaceutical Industries Ltd (Petah Tikva, Israel).

Availability of data and material Qualified researchers may request access to patient-level data and related study documents including the study protocol and the statistical analysis plan. Requests will be reviewed for scientific merit, product approval status, and conflicts of interest. Patient-level data will be de-identified, and study documents will be redacted to protect the privacy of trial participants and to protect commercially confidential information. Please email USMedInfo@ tevapharm.com to make your request. 
Code availability (software application or custom code) n/a.

\section{Declarations}

Conflict of interest Authors FS, PSL, MFG, and LRG are employees of Teva Pharmaceutical Industries Ltd which acquired deutetrabenazine from Auspex Pharmaceuticals, Inc., La Jolla CA. Authors DS and MJB are former employees of Teva Pharmaceutical Industries Ltd and were employees at Auspex Pharmaceuticals at the time the studies were conducted.

Open Access This article is licensed under a Creative Commons Attribution 4.0 International License, which permits use, sharing, adaptation, distribution and reproduction in any medium or format, as long as you give appropriate credit to the original author(s) and the source, provide a link to the Creative Commons licence, and indicate if changes were made. The images or other third party material in this article are included in the article's Creative Commons licence, unless indicated otherwise in a credit line to the material. If material is not included in the article's Creative Commons licence and your intended use is not permitted by statutory regulation or exceeds the permitted use, you will need to obtain permission directly from the copyright holder. To view a copy of this licence, visit http://creativecommons.org/licenses/by/4.0/.

\section{References}

1. Huntington Study Group, Frank S, Testa CM et al (2016) Effect of deutetrabenazine on chorea among patients with Huntington disease: an randomized clinical trial. JAMA 316:40-50

2. Huntington Study Group (2006) Tetrabenazine as antichorea therapy in Huntington disease: a randomized controlled trial. Neurology 66:366-372

3. Fernandez HH, Factor SA, Hauser RA et al (2017) Randomized controlled trial of deutetrabenazine for tardive dyskinesia. Neurology 88:2003-2010

4. Anderson KE, Stamler D, Davis MD et al (2017) Deutetrabenazine for treatment of involuntary movements in patients with tardive dyskinesia (AIM-TD): a double-blind randomized placebocontrolled phase 3 trial. Lancet Psychiat 4:595-604

5. Schneider F, Bradbury M, Baillie TA et al (2020) Pharmacokinetic and metabolic profile of deutetrabenazine (TEV-50717) compared with tetrabenazine in healthy volunteers. Clin Transl Sci 13:707-717
6. Schneider F, Stamler D, Bradbury M et al (2020) Pharmacokinetics of deutetrabenazine and tetrabenazine: dose proportionality and food effect. Clin Pharmacol Drug Dev 0(0):1-13

7. Lundbeck Inc (2011) US prescribing information: xenazine (tetrabenazine) tablets [online]. Available from URL: http://www. lundbeckinc.com/USA/products/CNS/xenazine/usa_xen_pi.pdf [Accessed 2011 Jul 20]

8. Jankovic J, Clarence-Smith K (2011) Tetrabenazine for the treatment of chorea and other hyperkinetic movement disorders. Expert Rev Neurother 11:1509-1523

9. Scott L (2011) Tetrabenazine for chorea associated with Huntington's disease. CNS Drugs 25:1073-1085

10. FDA (2021) Guidance for industry suicidal ideation and behavior: prospective assessment of occurrence in clinical trials. https:// www.fda.gov/media/79482/download August 2012. Last accessed July 132021

11. PAXIL (2021) Paroxetine hydrochloride. Glaxco Smith Kline. https://www.accessdata.fda.gov/drugsatfda_docs/label/2012/ 020031s067\%2C020710s031.pdfLast accessed July 26, 2021

12. Jeppesen U, Gram LF, Vistisen K et al (1996) Dose-dependent inhibition of CYP1A2, CYP2C19 and CYP2D6 by citalopram, fluoxetine, fluvoxamine and paroxetine. Eur J Clin Pharm 51:73-78

13. Alfaro CL, Lam YWF, Simpson J et al (2000) CYP2D6 Inhibition by fluoxetine, paroxetine, sertraline and venlafaxine in a crossover study: Intraindividual variability and plasma concentration correlations. J Clin Pharmacol 40:58-66

14. Storelli F, Matthey A, Lenglet S et al (2018) Impact of CYP2D6 functional allelic variations on phenoconversion and drug-drug interactions. Clin Pharmacol Ther 104:148-157

15. Laine $\mathrm{K}$, Tybring $\mathrm{G}$, Hartter $\mathrm{S}$ et al (2001) Inhibition of cytochrome P4502D6 activity with paroxetine normalizes the ultrarapid metabolizer phenotype as measured by nortriptyline pharmacokinetics and the debrisoquin test. Clin Pharmacol Therapeut 70:327-335

16. Dean M, Sung V (2018) Review of deutetrabenazine: a novel treatment for chorea associated with Huntington's disease. Drug Des Devel Ther 2:313-319

Publisher's Note Springer Nature remains neutral with regard to jurisdictional claims in published maps and institutional affiliations. 